\title{
Coulisses
}

Revue de théâtre

15 | Hiver 1997

Varia

\section{L'Annonce faite à Marie : du Château de Joux à la cathédrale Saint Jean}

Thérèse Favrot

\section{(2) OpenEdition}

1 Journals

Édition électronique

URL : http://journals.openedition.org/coulisses/5094

DOI : $10.4000 /$ coulisses.5094

ISSN : 2546-9460

Éditeur

Presses universitaires de Franche-Comté

\section{Édition imprimée}

Date de publication : 1 janvier 1997

Pagination : 47

ISSN : 1150-594X

\section{Référence électronique}

Thérèse Favrot, "L'Annonce faite à Marie : du Château de Joux à la cathédrale Saint Jean », Coulisses

[En ligne], 15 | Hiver 1997, mis en ligne le 26 avril 2019, consulté le 25 octobre 2019. URL : http:// journals.openedition.org/coulisses/5094; DOI : 10.4000/coulisses.5094

Ce document a été généré automatiquement le 25 octobre 2019.

Coulisses 


\title{
L'Annonce faite à Marie : du Château de Joux à la cathédrale Saint Jean
}

\author{
Thérèse Favrot
}

1 Pierre Louis, animateur du Centre d'Animation du Haut-Doubs et des Nuits de Joux, vient de présenter, les 14 et 15 novembre, le spectacle qu'il avait donné en juillet 95 au Château de Joux, le chef d'œuvre de Paul Claudel, qui est aussi la pièce la plus représentée de cet auteur - et ceci dans le monde entier : L'Annonce faite à Marie, et ces représentations avaient obtenu un très beau succès.

Il est bien évident que le fait de passer du si beau décor de plein air de la grande cour du château (que le metteur en scène avait utilisé d'ailleurs avec beaucoup de bonheur) à un espace clos, plus restreint (un plateau simplement ceint de draperies noires) modifie la vision que nous avions eue du spectacle, Pierre Louis s'étant trouvé dans l'obligation de l'adapter à son nouveau cadre qui le prive de la poésie du premier. Il faut ajouter aussi que certains interprètes ne sont plus les mêmes. Il résulte de ces changements un spectacle différent, avec des plus et des moins pour chacune des deux versions.

2 À l'avantage de Besançon :

- Le fait que les acteurs se trouvent plus près du public,

- que deux des acteurs de la création, ayant eu la possibilité de se familiariser davantage avec leur personnage, l'ont approfondi avec beaucoup de sensibilité. Il s'agit de Claudine Berthet, dans la mère, et de Christian Pageault qui, dans Anne Vercors, de bon est devenu excellent.

- enfin Mathieu Loiseau, nouveau venu, qui vit Pierre de Craon avec tant de passion et de douleur vraies qu'il me semble difficile de trouver pour ce rôle un meilleur interprète.

3 À l'avantage de Joux :

- La mise en scène en général, qui donnait l'impression d'une grande spontanéité : je pense en particulier aux interventions des villageois, chanteurs et musiciens - que Pierre Louis avait ajoutés au spectacle, auquel ils s'intégraient bien, grâce à la largeur et surtout la profondeur du plan scénique. Il ne peut les utiliser ici de la même façon, et leurs interventions, immobiles devant la scène, paraissent plaquées. 
4 Mais la plus grave réserve concerne les deux interprètes principales, Lorraine Prigent : Violaine, et Béatrice Bompas: Mara, toutes les deux n'appartenant qu'à la seconde distribution. Comme sa devancière Lorraine Prigent ne parvient pas à faire évoluer son personnage vers la gravité et la dimension mystique de Violaine - qu'elle rend de façon trop légère. Quant à Béatrice Bompas, si elle possède de réelles qualités d'intelligence et de sensibilité, son manque de moyens ne lui permet pas de donner la force de Mara alors que l'actrice qui l'avait précédée dans le rôle en avait remarquablement exprimé la violence. La grande explication et confrontation entre les deux sœurs, dans le bois de Chevoche aboutissant à la résurrection de la petite Aubaine, était véritablement poignante. Cette fois-ci, on ne se sent pas accroché par une scène toute en demi-teintes, qui est dite, d'ailleurs, de façon si confidentielle qu'elle est souvent difficilement audible.

\section{AUTEURS}

\section{THÉRÈSE FAVROT}

Auditeur de l'Université Ouverte 